\title{
Effects of the Three Gorges Project on the Environment of Poyang Lake
}

\author{
Dayong Li ${ }^{1 *}$, Xijun Lai ${ }^{2}$, Zengchuan Dong ${ }^{1}$, Xiaoli Luo ${ }^{1}$
}

${ }^{1}$ College of Hydrology and Water Resources, Hohai University, Nanjing 210098, China

${ }^{2}$ State Key Laboratory of Lake Science and Environment, Nanjing Institute of Geography and Limnology Chinese Academy of Sciences, Nanjing 210008, China

Received: 6 April 2016

Accepted: 14 May 2016

\begin{abstract}
Impounding by the Three Gorges Project (TGP) changed the hydrological process and affected the ecosystem in the middle and lower reaches of the Yangtze River. Poyang Lake is closely linked with the Yangtze River. This paper presents a coupled numerical model designed for simulating the tempo-spatial variation of water quantity and quality in the lake's water system that features complex river-lake interactions. According to the calculated results of a typical year (2000) under two scenario schemes, we evaluated TGP's effects on the ecological environment of the lake. The results show that due to TGP impoundment, the hydraulic gradient at the lake outlet has increased and that the outflow fluctuates dynamically and regularly with the increase and decrease of the TGP released discharge. The lake water level falls in advance and the average reduction magnitude of the water level decreases progressively from north to south, showing a spatially uneven effect, which is $0.95 \mathrm{~m}, 0.70 \mathrm{~m}, 0.74 \mathrm{~m}, 0.35 \mathrm{~m}$, and $0.80 \mathrm{~m}$ at Xingzi, Tangyin, Duchang, Kangshan, and Wucheng stations, respectively. The ammonia nitrogen output from the lake to the Yangtze River increases and the total ammonia nitrogen amount within the lake region decreases. The average ammonia nitrogen concentration within the lake region tends to increase slightly and the influence magnitude on the concentration is reduced from north to south. The wetland vegetation area fluctuates dynamically with the decline of the water level, and the increase of the wetland vegetation area ranges from 0.64 to $215.48 \mathrm{~km}^{2}$. As a result of the falling water levels, the bottomlands in the lake region are exposed relatively earlier and the continuous exposure days increase, which intensifies the problem that migrant birds do not have enough food. Meanwhile the number of days when the bottomland and wetland are submerged decrease, which will further accelerate the degradation succession of wetland vegetation.
\end{abstract}

Keywords: the Three Gorges Project, Poyang Lake, impounding effects, numerical model, water ecological environment

*e-mail: lidayong1975@163.com 


\section{Introduction}

The Three Gorges Project (TGP) is located in Sandouping of Yiling town belonging to Yichang city, which forms the cascade hydroelectric power station dispatching system together with the downstream Gezhouba hydropower station. TGP is the world's largest hydropower station and also China's largest construction project, which will bring a series of complex effects to the Yangtze River Basin [1-2]. Poyang Lake is one of two biggest lakes still linked with the Yangtze, which is not only the natural storing of the Yangtze River flood and an important wetland of the world, but also a significant region of biodiversity for the Yangtze [3-4]. The TGP operation has changed the temporal distribution of the incoming water from the upper reaches of the Yangtze [5-6] and caused the change of water regime of Poyang [7-9], which will further lead to changes in water ecological environment. As a result, the development of water resources, conservation of wetland ecology, and biological diversity in Poyang will be directly affected, and even sustainable use of water and protection of the Yangtze environment may be involved [10].

The TGP effects on Poyang have appeared when TGP has been in operation since 2003. Extreme drought of the Poyang region has happened several times in recent years, beginning when TGP began to store water in 2006 [11]. The impacts of the TGP impounding on water regime and the water ecological environment of Poyang have been cause for concern. Based on extensive hydrological data, a generalized linear statistical model has been established to demonstrate that the TGP operation induces major changes in the downstream river discharge near the dam, and to reveal the considerable effects on water levels of Poyang - particularly a reduced level over the dry period from late summer to autumn [12].

Changes in Yangtze River discharge caused by TGP have further altered the interrelationship between the river and the lake, disturbing the lake basin hydrological processes and water resources [13]. Using a new coupled hydrodynamic analysis model (CHAM) designed for simulating a large-scale water system in the middle Yangtze River Basin, we investigated the storage effects of TGP on lake outflow and water level, and we clarified the dynamic mechanism for the hydrological responses of Poyang to TGP impoundment based on the typical case study [14].

The water level change of Poyang Lake by TGP operation was calculated using the hydrological method under the conditions of the four typical hydrological years (1998, 2000, 2004, and 2006), and we found that due to the water storing of TGP, the water level of Hukou would fall 0.4-1.6 $\mathrm{m}$ and that inside Poyang Lake wound fall 0.3-1.2 $\mathrm{m}$ [15]. Using a probability analysis method based on the multivariate copula function of the joint distribution, the change of water level in Poyang was investigated under the three scheduling schemes during the TGP impoundment [16]. Using the hydrological method, the lowest water level of Poyang for a long time in 2006 was caused by the decrease in inflow from upstream of the Yangtze, and the decrease of inflow from the five rivers in autumn and TGP storage from September to October [17]. We developed a 1-D model of flood routing for the Yangtze in order to investigate the influence of the TGP operation on Poyang water levels, and we found that the water level will drop 0.06-0.82 $\mathrm{m}$ when the operation of TGP in flood season reduces the discharge of $1,000-6,000 \mathrm{~m}^{3} / \mathrm{s}$, and finally a conclusion is given that the TGP operation will have different impacts on flood control, scouring and silting, beach exposure, environment for birds, and other related aspects [18]. The coupled water flow and sediment simulation model was developed and applied to quantitatively predict the variation of channel erosion and deposition in the middle and lower reaches of the Yangtze under the assumption of the TGP operation for 10 years, and the influencing analysis on the water level of Poyang was made during the water storage period [19]. Although the wetland was in a positive succession before the operation of TGP, the effects on the succession of the wetlands were very different depending on the distance from Hukou after the operation of TGP. The succession of the Raohe River wetland near Hukou was changed, which was obviously affected by the TGP operation, and as a result of falling water levels, the range of Carex Beach has greatly extended because the time when the wetland was exposed has been moved up [20].

$\mathrm{Hu}$ et al. have developed a rule-based model based on time-series MODIS imagery to simulate the wetland vegetation pattern responding to water level changes in Poyang before and after TGP impoundment [21]. Most existing research achievements are currently focused on the water regime change of Poyang Lake under TGP operation. Despite the fact that a more unified qualitative conclusion has been drawn that the Poyang water level tends to decrease with the reduction of TGP-released flow, there are some differences in quantity because the technical and analytical methods adopted by many researchers are different from each other. In particular, the influence mechanism of the TGP impounding on the water regime change of Poyang still needs to be further strengthened. The Poyang water regime changes will further affect the water mass transport process, leading to a change in the water environment, but as a whole the quantitative research is not enough and the question remains regarding the characteristics and variations of water quality under the influence of TGP impounding. Although the impacts of the water regime change on the water ecological environment of Poyang are analyzed from the macroscopic perspective in most literature, there is still a lack of the necessary quantitative analysis or enough data support.

In view of this, the tempo-spatial variation process of Poyang water level and water is simulated in this paper under two scenario schemes using a coupled numerical model designed for the lake's water system. In terms of quantitative and qualitative methods, the TGP effects on the water level, the Hukou river discharge, and the water quality of Poyang Lake are emphatically analyzed and the dynamic mechanism of the Hukou outflow during the TGP 
impounding is further discussed. Finally, based on the accessible remote sensing data and the calculated water level data, we investigated the impact of TGP impounding on Poyang wetland vegetation, and analyzed the impact on the bottomlands and wetlands at Xingzi, Duchang, and Wucheng stations.

\section{Materials and Methods}

\section{Study Area}

Poyang Lake (Fig. 1) is China's largest freshwater lake with a water area of $2,933 \mathrm{~km}^{2}$. It is located on the south bank of the middle and lower Yangtze, 1,050 km downstream of the TGP. The lake is naturally linked with the middle Yangtze, and their strong river-lake interactions formed complex hydrological characteristics [22]. Bound by Songmen Mountain, Poyang has the shape of gourd, and the southern part is the main body of the lake, which is wide and shallow while the north part is a narrow and deep waterway connecting with the Yangtze.

Five great rivers - the Ganjiang, Fu, Xinjing, Rao, and Xiu - and other streams, such as the Boyang and Zhangtian rivers, flow into Poyang, and after regulation and storage there is about 143.6 billion $\mathrm{m}^{3}$ water being injected annually into the Yangtze through the lake's outlet to the north. Surrounded by mountains, the lake terrain is higher in the south than that of the northern part, and the surroundings incline to the lake gradually. The water level of Poyang fluctuates a lot by season. The water level rises during the flood period, leading to a rapid increase of the lake level, while it is the opposite in the dry season,

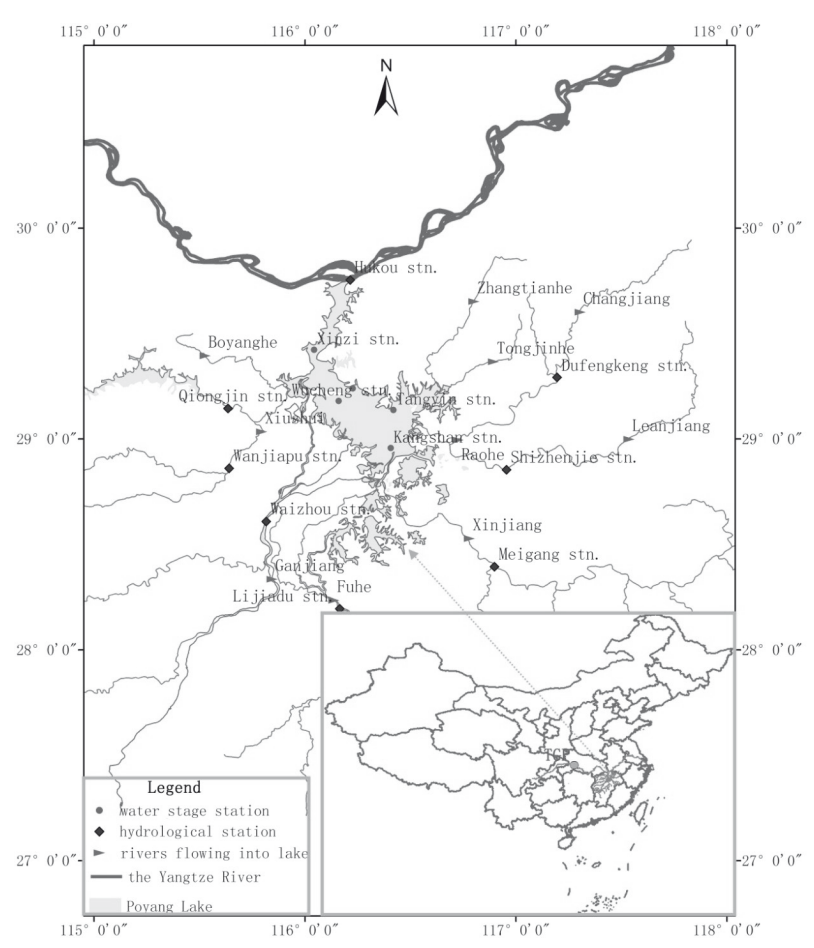

Fig. 1. Map of water system in Poyang Lake region. especially in winter, when a large number of shallow depressions and marshlands emerge as the main habitats and foraging places for winter migratory birds [23].

\section{Study Method}

\section{2-D Water Quantity and Quality Control Equation}

Under the assumption of hydrostatic pressure, integrating 3-D Navier-Stokes equation along the water depth can the average water depth 2-D water flow and water quality control equations. In the equation, the free water surface elevation depth $\xi$ is used to replace water depth $h$ as the dependent variable, which can solve the computation destabilization caused by rapid elevation variation. The conservative forms of the equations are described as follows [24]:

$$
\frac{\partial U}{\partial t}+\nabla \cdot F(U)=Y
$$

...where $U$ is the conserved physical vector, and $F_{x}$ and $F_{y}$ are the flux vectors in the $x$ and y directions given below

$$
\begin{gathered}
U=[\xi, h u, h v, h C]^{T} \\
F_{x}=\left[h u, h u+\left(\xi^{2}+2 \xi h_{s}\right) \cdot g / 2, h u v, h u C\right]^{T} ; \\
F_{y}=\left[h v, h u v, h v^{2}+\left(\xi^{2}+2 \xi h_{s}\right) \cdot g / 2, h v C\right]^{T}
\end{gathered}
$$

$Y$ is the vector for source/sink term written by:

$Y=\left[\begin{array}{l}0, g \xi S_{o x}-g h S_{f x}+\nabla^{2} \varepsilon h u+c_{w} \rho_{a} w^{2} \sin \beta / \rho^{2}+f v h, g \xi S_{o y}-g h S_{f y}+ \\ \nabla^{2} \varepsilon h v+c_{w} \rho_{a} w^{2} \cos \beta / \rho^{2}-f u h, \nabla \cdot\left(D_{i} \nabla(h C)\right)+\frac{h S}{86400}+S_{w}\end{array}\right]^{T}$

...in which $\xi$ is the free water surface elevation depth, $h$ denotes water depth, $h_{s}=h-\xi$ is the distance from the base level to the bed bottom, $u$ and $v$ denote the depthaveraged velocity components in the $\mathrm{x}$ and $\mathrm{y}$ directions (respectively), $S_{0 x}=\partial z_{b} / \partial x$ and $S_{f x}=\rho n^{2} u \sqrt{u^{2}+v^{2} /} h^{4 / 3}$ are the bed slope and friction slope in the $\mathrm{x}$ direction (respectively), $S_{0 y}=\partial z_{b} / \partial y$ and $S_{f y}=\rho n^{2} v \sqrt{u^{2}+v^{2}} / h^{4 / 3}$ are the bed slope and friction in the y direction (respectively), $g$ is gravitational acceleration, $\rho_{a}$ is air density, $w$ is wind velocity, $\beta$ is the angle between wind direction and $\mathrm{y}$ axis, $c_{w}$ is the wind drag coefficient, $\rho$ is water density, $\varepsilon$ is kinematical viscosity coefficient, $f$ is the Coriolis coefficient, and $D_{x}$ and $D_{y}$ are the pollutant diffusion coefficients. Other variables are the same as the former.

\section{1-D Water Quantity and Quality Control Equation}

The 1-D Saint-Venant equation set is used to simulate the river water flow movement of the river network, and 
the 1-D convection-diffusion equation is used to describe the transport of water quality components. They can be written as follows [25-26]:

$$
\begin{gathered}
\left\{\begin{array}{l}
\frac{\partial Q}{\partial x}+B_{T} \frac{\partial Z}{\partial t}=q_{L} \\
\frac{\partial Q}{\partial t}+\frac{\partial}{\partial x}\left(\alpha \frac{Q^{2}}{A}\right)+g A \frac{\partial Z}{\partial x}+g A \frac{Q|Q|}{K^{2}}=q_{L} v_{x}
\end{array}\right. \\
\frac{\partial(A C)}{\partial t}+\frac{\partial(Q C)}{\partial x}=\frac{\partial}{\partial x}\left(A E_{x} \frac{\partial C}{\partial x}\right)+\frac{A S}{86400}+S_{w}
\end{gathered}
$$

...in which $x$ denotes the distance in $\mathrm{x}$ direction, $t$ is the time variable, $Q$ and $Z$ are the section average discharge and water level (respectively), $\alpha$ is the momentum correction coefficient, $K$ is the discharge modules, $q_{L}$ is the lateral inflow per river length, $v_{x}$ is the inflow velocity along water movement direction, $A$ is the wetted crosssectional area, $B_{T}$ is the total water surface width, $C$ is the concentration variable for general water quality components, $E_{x}$ the longitudinal dispersion coefficient, $S$ is the biochemical reaction terms of selected types of water quality indicators, and $S w$ is the exterior source and sink terms.

\section{Model Solving and Coupling}

The program flow chart designed for the Poyang Lake region water system is shown in Fig. 2. The unstructured grid finite volume method FDS is used to solve the 2-D equation and the average Riemann approximate solution is adopted to estimate the interface flux [27]. The 1-D equation is discretized by using the Preissmann weighted implicit four-point finite-difference scheme, together with the linearization process for nonlinear terms, and finally the linear discretization algebraic equation set is obtained. Adopting the discharge continuity and energy conservation conditions imposed on nodes and combining with linearization equation of all kinds of hydraulic structures, the water level equation sets of node are finally established. The PGMRES method is used to solve the equation and the water level of all nodes are obtained, and all the section discharges and water levels are finally obtained through the backward process [28-29]. In 1-D convection and diffusion equations a convective term is discretized by using an implicit upwind difference scheme, and the diffusion term is discretized by using the central difference scheme. Taking the flow direction of a river into consideration and combining with the node concentration balance equation, the linear algebraic equation set for node concentration is obtained. Finally, the concentration of each node is also obtained based on the PGMRES method, and all section concentrations are finally obtained through the backward process.

The accurate convergence of different model interfaces is one of the key factors for simulating unsteady water quantity and quality for large-scale water systems. In this paper, the overlapping projection method is used to set the coupling zone in the common boundary point of the 1-D and 2-D water area, where the operation of accurate solution projection is implemented [30]. In this paper, the coupling of water level, flow rate, and water quality are designed in three ways, and the connections between water level, water quality, and geometric elements must be coordinated.

\section{Constructing the Water Quantity and Quality Model for Poyang Lake River System}

The modeling region consists of the Poyang Lake area, the Xiushui River from Wanjiapu Station and Qiujin station to the lake area, the Ganjiang River from Waizhou Station to the lake area, the Fu River from Lijiadu Station to the lake area, the Xinjiang River from the Meigang Station to the lake area, the Rao River from Shizhenjie and Dufengkeng stations to the lake area, and the Boyang, Zhangtian, and Tongjin rivers.

\section{Modeling System Generalization}

The division of the river section, the determination of the modeling area boundary, the mesh generation of the lake area, and the grid interpolation of the lake bottom

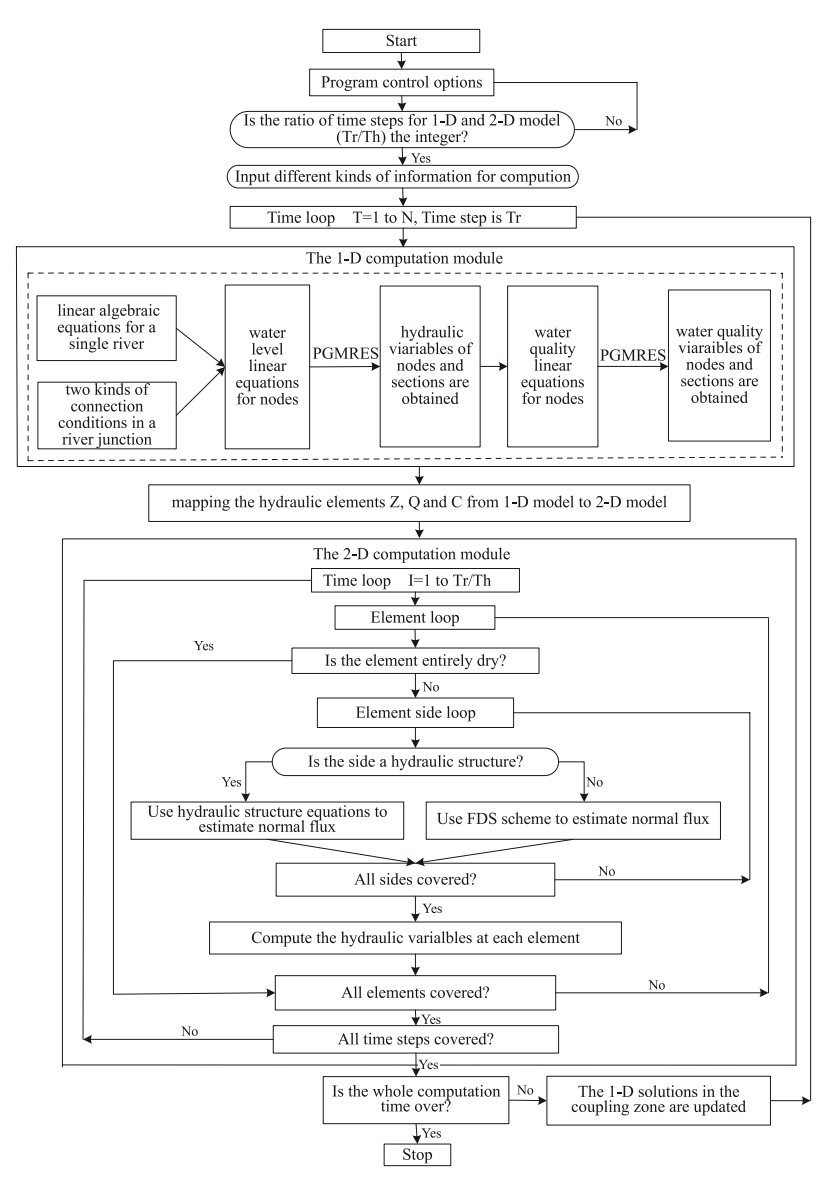

Fig. 2. Program flow chart designed for a coupled numerical model. 


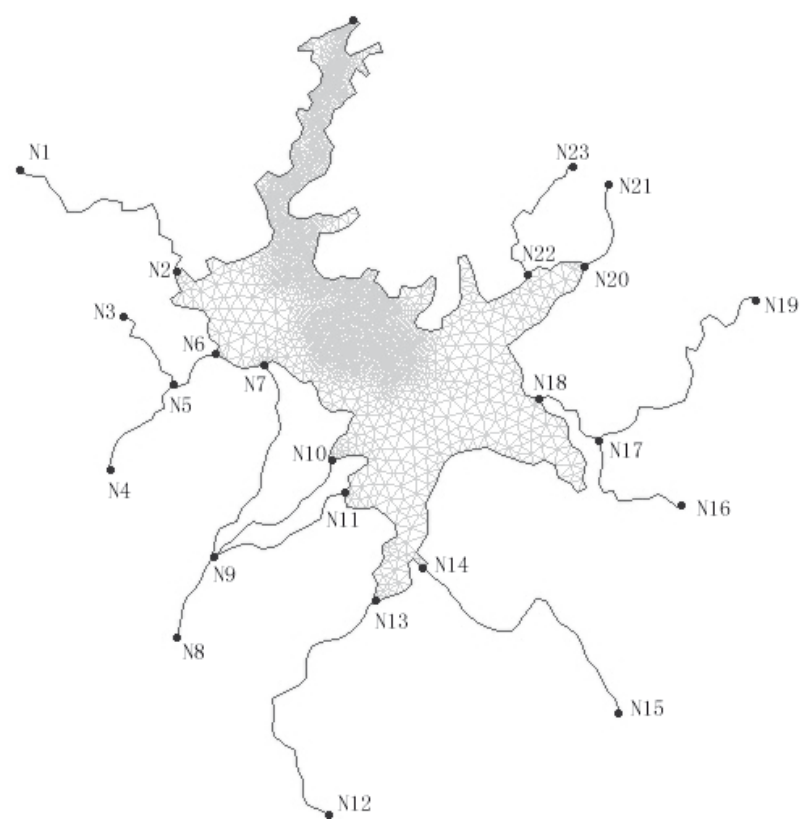

Fig. 3. Generalization of hydrodynamic model of Poyang Lake river system.

elevation were carried out according to the actual measured data in 1995. The model system is generalized as shown in Fig. 3. All the rivers were generalized into 23 nodes, 15 reaches, and 83 sections (with section spacing of about $2-3 \mathrm{~km}$ ). The lake region is a 2-D calculation area subdivided by triangular mesh and encrypted appropriately according to the terrain. Finally, 5,252 grid cells and 2,825 nodes were obtained, and the grid step size is from 0.5 to $1.5 \mathrm{~km}$.

\section{Dealing with a Moving Boundary}

The water regime of Poyang Lake in both flood season and dry season has a big difference on the large variation range of water levels, leading to the inundation and exposure of the beach alternatively. Dynamically dealing with the moving boundary is one of the key parts for establishing the hydrodynamic model. According to the characteristics of the finite volume method, the water depth is designed as the discrimination criteria to set up the type of element interface, and the corresponding methods are used to calculate the normal fluxes across the element interfaces so that mass and momentum balances can be maintained [27]. The depths at the two sides of an element are judged at each time step. When water depths on both sides of an element are zero, the flux is zero, and when either of them is zero, many analytic solution formulas such as instantaneous dam break and weir can be chosen to estimate the flux through the element interface according to the boundary conditions, which may be rigid boundary, drop and cross flow, and so on. When both of them are non-zero, the normal ways are used to estimate the flux through the element interface. The water depth tolerance is set at about $0.01 \mathrm{~cm}$, which is treated as criteria to determine whether an element is entirely dry, partially dry, or wet. If the water depths of the adjacent units are less than that, the particular unit is considered to be dry, which is excluded from the computation.

Similarly, with the water level fluctuation in both flood season and dry season, the zero flow situations that may appear among the interior channels will result in computation termination unless it is handled in a particular way. When the water level of the head node and tail node are less than the bottom elevation of the corresponding section, the channel is frozen and excluded from the river network calculation, otherwise the hydrological elements of this channel are normally calculated. If the water depth of this channel is negative, the channel is frozen and recalculated.

\section{Definite Conditions}

\section{1) Initial conditions}

Initial conditions for water quantity calculation: The initial values of water level for nodes in the river network system are set according to the measured data of the neighboring hydrological (stage) stations, and then the coupled model is activated under the condition of steady flow condition and the initial discharge and water level of all the sections can be obtained. If the error is bigger, the local adjustment should be carried out. The initial values of water level for the 2-D elements are set according to water level values of the five representative hydrological (stage) stations in the Poyang Lake area, and the initial flow of every element is set at zero.

Initial conditions for water quality calculation: Based on the water quality monitoring data measured before the calculation starting time in the lake region, the interpolation method is used to obtain the initial values of water quality for the 2-D elements. The initial values of water quality for the river cross-sections are also set according to the water quality monitoring data measured before the calculation starting time in the corresponding water quality monitoring stations.

2) Boundary conditions

Boundary conditions for water quantity calculation: The stage-discharge relationship at Hukou station is taken to reflect the interactions between Poyang and the Yangtze. The discharge processes of Waizhou Station in the Ganjiang River, Lijiadu Station in the Fu River, and Meigang Station in the Xinjiang River are used as boundary control. The Xiu River is divided into two tributaries flowing into Poyang, so Qiujin and Wanjiapu stations are taken as boundary control. The discharge processes of Shizhenjie and Dufengkeng stations in the Rao River are treated as boundary control. Due to the lack of measured data, the discharge processes of the Zhangtian, Boyang, and Tongjin rivers are estimated using the analogy method of controlling area as boundary control, taking the corresponding discharge processes of Qiujin and Dufengkeng stations as reference.

Boundary conditions for water quality calculation: The water quality variation processes of the Ganjiang, $\mathrm{Fu}$, Xinjiang, Xiu, and Rao rivers at the corresponding 
hydrological stations are treated as the boundary control, which is synchronous with the discharge processes. The control boundary of water quality for the Zhangtian, Boyang, and Tongjin rivers are taken referring to the water quality variation processes of the adjacent hydrological stations.

\section{3) Model parameters}

a) River roughness coefficient

The river roughness coefficient is preliminarily given by referring the past experience derived from the flood routing computation of the middle and lower reaches of the Yangtze [31-33]. Considering that the river roughness coefficient varies with water depth, the different roughness coefficients are set up according to the corresponding water depth in this paper. Determining the roughness coefficient for all the elements is very difficult. It is obviously unreasonable that the 2-D element roughness coefficient in the different water levels pre-specifies the constant values. Therefore, the formula that determines the 2-D element roughness coefficient is adopted as follows: $n=n_{0} / h^{\alpha}$, in which $\alpha$ is the undermined parameter in this paper.

\section{b) Water quality parameters}

The water quality of the Poyang river system presents the characteristics of organic pollution [34]. Therefore, ammonia nitrogen is chosen as the index of water quality computation. The biochemical reaction terms of ammonia nitrogen are defined as follows:

$$
\mathrm{S}=k_{m} C_{n}-k_{n} C_{n}+\frac{S_{n}}{h_{n}}
$$

...where $k_{m}$ is the ammonia nitrogen mineralization rate coefficient for a river or lake, $\mathrm{d}^{-1}, k_{m}$ is equal to zero for river; $k_{n}$ is the ammonia nitrogen nitrification rate coefficient for river or lake, $\mathrm{d}^{-1} ; h_{n}$ is the average water depth of the 1-D river section or the 2-D lake element; $S_{n}$ is the ammonia nitrogen sediment release coefficient under aerobic conditions, $\mathrm{g} /\left(\mathrm{m}^{2} \cdot \mathrm{d}\right)$; and $C_{n}$ is the ammonia nitrogen concentration of the 1-D river section or the 2-D lake element, $\mathrm{mg} / \mathrm{l}$.

c) Diffusion coefficient

On the basis of the theoretical formula of the Fisher, combing with the water flow characteristics of the middle and low reaches of the Yangtze, a simplified formula suitable for the river network is derived as follows [35]:

$$
E_{x}=\beta C_{x} \theta^{2} q
$$

... where $C_{x}$ is the scale-free Chezy coefficient, $C_{x}=C_{0} / \sqrt{g}$; $\theta$ is the width depth ratio for river section, $\theta=B / h ; \beta$ is set to 0.01 in terms of the field and laboratory experiments; and $q$ is the river section average discharge of per unit width.

Pollutant diffusion in lake waters is mainly caused by physical action, and the pollutant diffusion coefficient can be calculated as follows [36]:

$$
D_{i}=\gamma_{i} h \sqrt{g h I}
$$

...where $h$ is the average water depth between the 2-D elements, $I$ is the lakebed gradient calculated by the lakebed topographical data, and $\gamma_{i}$ is the undetermined coefficient determined by the model calibration.

\section{Model Calibration and Verification}

1) Calibration and validation of the water quantity model In order to test whether the established model can reflect the actual water movement characteristics, this model is calibrated using the measured data of 1991. The calibration results of five stations are shown in Figs 4 and 5.

From the above comparison diagrams it can be seen that the calculated water level hydrograph is in good agreement with the measured water level hydrograph, except that the big errors occur between days 78 and 87 , and the peak and valley values of two kinds of water level hydrograph correspond respectively, and the fluctuation is consistent. The mean absolute errors of the calculated and measured values at Xingzi, Yintang, Duchang, Kangshan, and Wucheng stations are $0.45 \mathrm{~m}, 0.25 \mathrm{~m}, 0.38 \mathrm{~m}, 0.3 \mathrm{~m}$, and $0.31 \mathrm{~m}$, respectively, and the average relative errors are within $5.0 \%, 2.4 \%, 3.9 \%, 2.6 \%$, and $2.8 \%$, respectively. It is thus clear that this model can dynamically reflect the interactions between the Yangtze and Poyang, and can truly simulate the fluctuating process of the flood peak level for the Poyang Lake water system and match well as a whole.

The roughness coefficient was pre-specified the constant values before calculation, then it was adjusted repeatedly by means of the trial and error method, and finally the adjusted roughness coefficient is determined as follows: $\mathrm{n}_{0}$ is taken 0.022 and $\alpha$ is $1 / 6$; $\mathrm{n}$ values vary between 0.025 and 0.032 when water level is low, and $\mathrm{n}$ values vary between 0.02 and 0.025 when water level is high. This model is validated by using the measured data
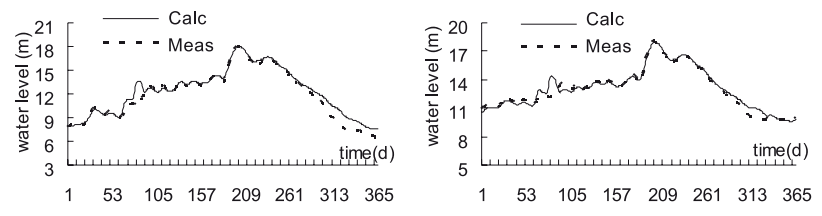

Fig. 4 Measured and calculated water level hydrograph of Xinzi and Tangyin Station.

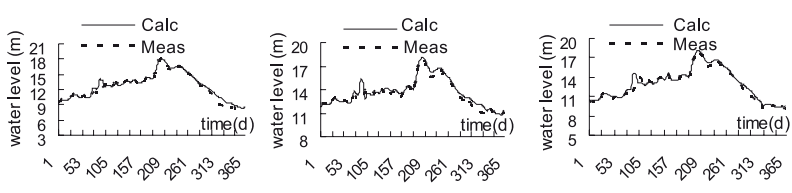

Fig. 5. Measured and calculated water level hydrograph of Duchang, Kangshan, and Wucheng stations. 

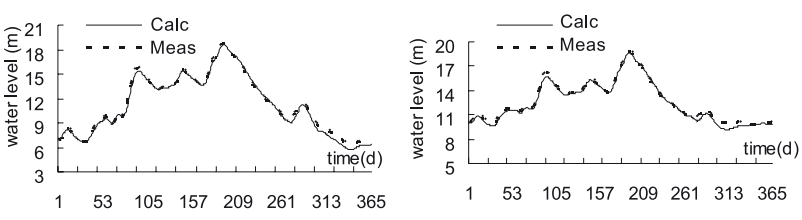

Fig. 6. Measured and calculated water level hydrograph of Xinzi and Tangyin stations.

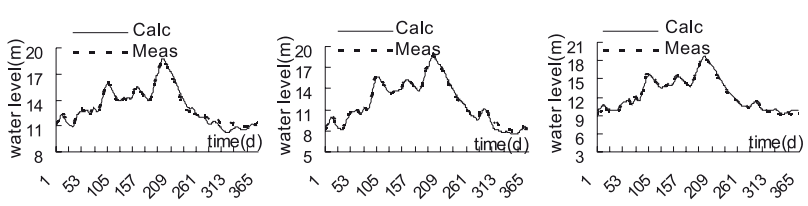

Fig. 7. Measured and calculated discharge hydrograph of Duchang, Kangshan, and Wucheng stations.

of 1992, and the roughness coefficient takes the adjusted value. The verification results of five stations are shown in Figs 6 and 7.

From the above comparison of the water level hydrograph we can see that other stations except Wucheng have a slightly big error during October to November, and as a whole the calculated water level hydrograph is in good agreement with the measured water level hydrograph, and the peak and valley of the measured stage hydrograph corresponds to that of the calculated stage hydrograph, and their fluctuations are consistent and the flood peak stages coincide better. The mean absolute errors between the calculated and measured data at Xingzi, Tangyin, Duchang, Kangshan, and Wucheng stations are $0.28 \mathrm{~m}$, $0.27 \mathrm{~m}, 0.26 \mathrm{~m}, 0.25 \mathrm{~m}$, and $0.22 \mathrm{~m}$, respectively, and the average relative errors are within $3.0 \%, 2.2 \%, 2.1 \%$, $2.4 \%$, and $1.9 \%$, respectively, and the maximum absolute errors are $0.80 \mathrm{~m}, 0.82 \mathrm{~m}, 0.85 \mathrm{~m}, 0.85 \mathrm{~m}$, and $0.70 \mathrm{~m}$, respectively, of which the maximum absolute error of Wucheng station occurs in the day 8 and that of all the other station occur between days 306 to 308 . It is thus clear that the established model can simulate the water movement characteristics and the changing trend of water levels for the lake's water system, and the selected parameters and some technical handling aspects are more reasonable, which can meet the requirements for further analysis.

2) Calibration and validation of water quality model

The parameters for the water quality model pre-specify the constant values by referring to the relevant research literature [37-38]. The parameters are calibrated based on the measured data of four stations (Wucheng station data is missing) in 1991, which are finally determined as follows: the ammonia nitrogen nitrification rate coefficient for river $k_{n r}$ is set to $0.18 \mathrm{~d}^{-1}$, and the sediment release coefficient for river $S_{n r}$ is taken as $0.02 \mathrm{~g} /\left(\mathrm{m}^{2} \cdot \mathrm{d}\right)$. The mineralization rate coefficient for lake $k_{m}$ is set to $0.08 \mathrm{~d}^{-1}$, and the nitrification rate coefficient $k_{n}$ for lake is $0.01 \mathrm{~d}^{-1}$, and the sediment release coefficient under aerobic conditions for lake $S_{n}$
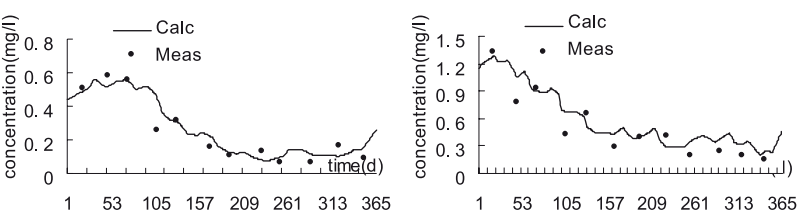

Fig. 8. Measured and calculated ammonia nitrogen hydrograph of Xingzi and Tangyin stations.
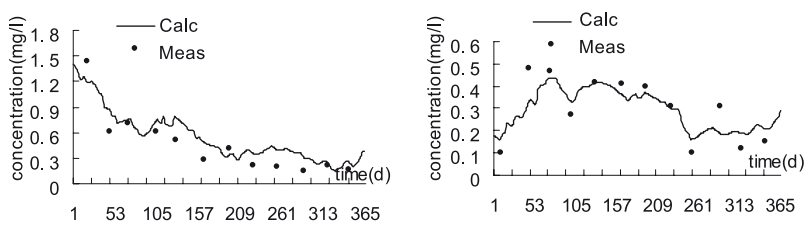

Fig. 9. Measured and calculated ammonia nitrogen hydrograph of Duchang and Kangshan stations.

is determined as $0.005 \mathrm{~g} /\left(\mathrm{m}^{2} \cdot \mathrm{d}\right)$, and other parameters such as $\gamma_{x}$ and $\gamma_{y}$ are set to 0.06 and 0.1 , respectively. The measured and calculated ammonia nitrogen hydrograph of four stations are shown in Figs 8 and 9.

From the above comparison of the ammonia nitrogen hydrograph it can be seen that the changing trends of the calculated and measured values are basically consistent. The average absolute errors between the calculated and observed data at Xingzi, Tangyin, Duchang, and Kangshan stations are $0.053 \mathrm{mg} / 1,0.123 \mathrm{mg} / 1,0.154 \mathrm{mg} / \mathrm{l}$, and $0.059 \mathrm{mg} / \mathrm{l}$, respectively, and the average relative errors are $34.8 \%, 36 \%, 48 \%$, and $28.9 \%$, respectively, and the maximum absolute errors are $0.2 \mathrm{mg} / \mathrm{l}, 0.24 \mathrm{mg} / \mathrm{l}$, $0.25 \mathrm{mg} / 1$, and $0.15 \mathrm{mg} / \mathrm{l}$, respectively, which appeared on days $106,107,130$, and 45 , respectively. The calibrated water quality model parameters are validated by using the measured data of 1992, and the validation results at five stations are shown in Table 1. The maximum relative errors between the calculated and measured data at Xingzi, Tangyin, Duchang, and Kangshan stations are 23.8\%, $11.7 \%, 20.9 \%$, and $12.1 \%$ respectively, the minimum relative errors are $23.8 \%, 11.7 \%, 20.9 \%$, and $12.1 \%$, and the average relative errors are $46.7 \%, 32.8 \%, 45.2 \%$, and $46.9 \%$, respectively. The above analysis shows that the water quality model is basically able to simulate the spatial and temporal variation of the ammonia nitrogen concentration in the Poyang Lake area, and the structure of the water quality model and the determination of the water quality parameters are reasonable.

\section{Remote Sensing Extraction of Wetland Vegetation Area in Poyang Lake}

Using the TM images of 2003 provided by America's Landsat [4-5, 7], the landmark spectrum characteristics and NDVI time series variation are comprehensively analyzed. The object-oriented classification technique is implemented in order to classify the Poyang wetland and the area of the main land use types in the Poyang 
Table 1. Comparison of measured and calculated ammonia nitrogen values at four stations.

\begin{tabular}{|c|c|c|c|c|c|}
\hline \multirow[b]{2}{*}{ Monitoring date } & \multicolumn{2}{|c|}{ Xingzi } & \multirow[b]{2}{*}{ Monitoring date } & \multicolumn{2}{|c|}{ Duchang } \\
\hline & $\begin{array}{l}\text { Measured value } \\
(\mathrm{mg} / \mathrm{l})\end{array}$ & $\begin{array}{l}\text { Calculated value } \\
(\mathrm{mg} / \mathrm{l})\end{array}$ & & $\begin{array}{l}\text { Measured value } \\
(\mathrm{mg} / \mathrm{l})\end{array}$ & $\begin{array}{l}\text { Calculated value } \\
(\mathrm{mg} / \mathrm{l})\end{array}$ \\
\hline April 12 & 0.11 & 0.181 & April 6 & 0.02 & 0.027 \\
\hline July 28 & 0.14 & 0.213 & July 28 & 0.11 & 0.173 \\
\hline September 19 & 0.10 & 0.156 & September 19 & 0.09 & 0.136 \\
\hline October 10 & 0.37 & 0.282 & October 10 & 0.48 & 0.424 \\
\hline November 12 & 0.29 & 0.364 & November 10 & 0.98 & 0.793 \\
\hline December 16 & 0.02 & 0.032 & December 13 & 0.15 & 0.184 \\
\hline \multirow[b]{2}{*}{ Monitoring date } & \multicolumn{2}{|c|}{ Duchang } & & \multicolumn{2}{|c|}{ Kangshan } \\
\hline & $\begin{array}{c}\text { Measured value } \\
(\mathrm{mg} / \mathrm{l})\end{array}$ & $\begin{array}{c}\text { Calculated value } \\
(\mathrm{mg} / \mathrm{l})\end{array}$ & Monitoring date & $\begin{array}{c}\text { Measured value } \\
(\mathrm{mg} / \mathrm{l})\end{array}$ & $\begin{array}{c}\text { Calculated value } \\
(\mathrm{mg} / \mathrm{l})\end{array}$ \\
\hline April 6 & 0.02 & 0.032 & March 13 & 0.43 & 0.378 \\
\hline July 28 & 0.06 & 0.102 & July 27 & 0.02 & 0.033 \\
\hline September 18 & 0.12 & 0.185 & September 18 & 0.10 & 0.152 \\
\hline October 10 & 0.33 & 0.261 & October 10 & 0.47 & 0.336 \\
\hline November 10 & 0.48 & 0.354 & November 9 & 0.15 & 0.239 \\
\hline December 13 & 0.02 & 0.028 & December 12 & 0.16 & 0.263 \\
\hline
\end{tabular}

Lake region. The seasonal changes of wetland vegetation during the year are added up according to the phonological difference analysis of vegetation communities of the region (Table 2).

From the above table, it can be seen that the change of wetland vegetation area with time in Poyang Lake has the following trend: during the winter until the flood season May, the vegetation coverage area increases continually, and after entering the flood season, are gradually submerged with the rise of water level, resulting in a decrease of the vegetation coverage area. After the flood season, the vegetation coverage area decreases with the descending water level. In fall and winter, the vegetation coverage area decreases for the reason that the vegetation wilts and decays.

\section{Setting the Numerical Calculation Scheme}

In order to assess the impacts of the TGP operation on Poyang, a scientific and objective assessment reference system is very important. On the basis of existing TGP operating rules, the period from September 26 to November 8 in 2000 were chosen as the research background. Considering that the TGP impoundment does not affect the inflow processes of other rivers for the Poyang Lake water system, two scenario schemes are set up in this paper as follows: 1) a prototype scheme that does not take into account the TGP operation. The boundary conditions at Hukou station are provided by the calculation results of the CHAM-Yangtze model under the condition of the TGP non-scheduling [33], and other boundary conditions

Table 2. Relationship of wetland vegetation area to season and water level.

\begin{tabular}{|c|c|c|c|c|c|}
\hline Date & $\begin{array}{l}\text { Water level at Xinzi } \\
(\mathrm{m})\end{array}$ & $\begin{array}{l}\text { Wetland vegetation area } \\
\qquad\left(\mathrm{km}^{2}\right)\end{array}$ & Date & $\begin{array}{l}\text { Water level at Xinzi } \\
\text { (m) }\end{array}$ & $\begin{array}{l}\text { Wetland vegetation } \\
\text { area }\left(\mathrm{km}^{2}\right)\end{array}$ \\
\hline January 8 & 6.92 & 196.96 & June 19 & 12.99 & 509.25 \\
\hline January 17 & 8.99 & 494 & August 6 & 15.07 & 140.5 \\
\hline January 28 & 8.52 & 321.75 & September 23 & 14.55 & 499.75 \\
\hline February 6 & 9.24 & 396.25 & October 16 & 12.79 & 797.25 \\
\hline April 27 & 11.91 & 868.5 & October 24 & 11.56 & 991.66 \\
\hline May 5 & 10.36 & 1181.04 & October 31 & 9.76 & 1001.46 \\
\hline May 31 & 15.09 & 457.25 & November 29 & 8.27 & 915.25 \\
\hline
\end{tabular}


and initial conditions are determined by the definite conditions based on measured hydrological data in 2000 . 2) a scheduling scheme that takes into account the TGP operation. The boundary conditions at Hukou station are provided by the calculation results of the CHAM-Yangtze model under the conditions of TGP scheduling, and other boundary conditions and initial conditions are the same as for the prototype scheme. Obviously, the prototype scheme is the reference system for the scheduling scheme, and the differences between the model operation results under two scenarios reflect the influence of the TGP operation on the changing hydrological factors in Poyang Lake.

\section{Results and Discussion}

\section{Influence of the Water Regime Change of Hukou on the Poyang Lake Region}

Under the influence of the TGP impoundment, the incoming discharge of the Yangtze is reduced, leading to an obvious change in water regime at the outlet of Poyang Lake. According to the water level hydrograph at Hukou Station (Fig. 10), the impact of the TGP impoundment on Hukou station has a time lag of 6-7 days. From about October 2, the TGP impoundment begins to affect the water regime at Hukou station, until 10 days after the end of impoundment (namely around November 17) the impoundment influence is basically over (when the difference of water level is less than $0.2 \mathrm{~m}$ under scenario schemes). The maximum water level difference is $1.505 \mathrm{~m}$, which appears on October 23. The level at Hukou dropped dramatically after the TGP impoundment, with the result that the water level difference between Xingzi and Hukou stations increased significantly.

On October 23 the measured water level difference between the two stations is merely $0.12 \mathrm{~m}$, while the water level difference reaches $0.48 \mathrm{~m}$ under the scheduling scheme. According to the discharge hydrograph at Hukou (Fig. 11), it can be seen that from October 3 to October 20 the discharge shows an increasing process of positive increments, and the average discharge increases $1,207 \mathrm{~m}^{3} / \mathrm{s}$, and the maximum value of the discharge increase is $2,199 \mathrm{~m}^{3} / \mathrm{s}$, which appeared on October 20 ,

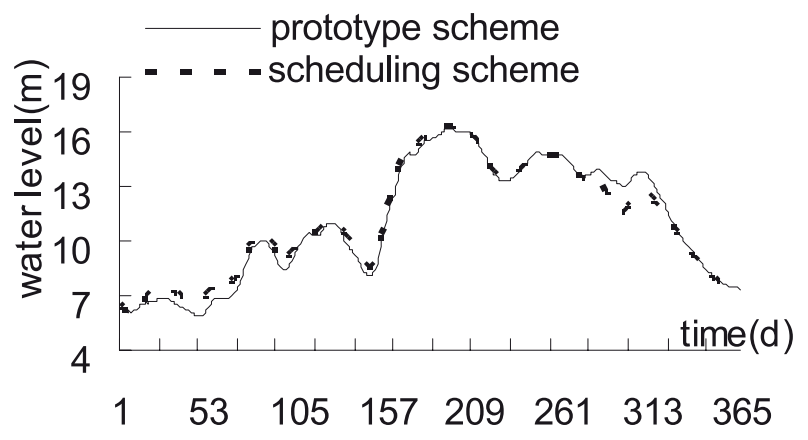

Fig. 10. Water-level hydrograph at Hukou station under scenario schemes.

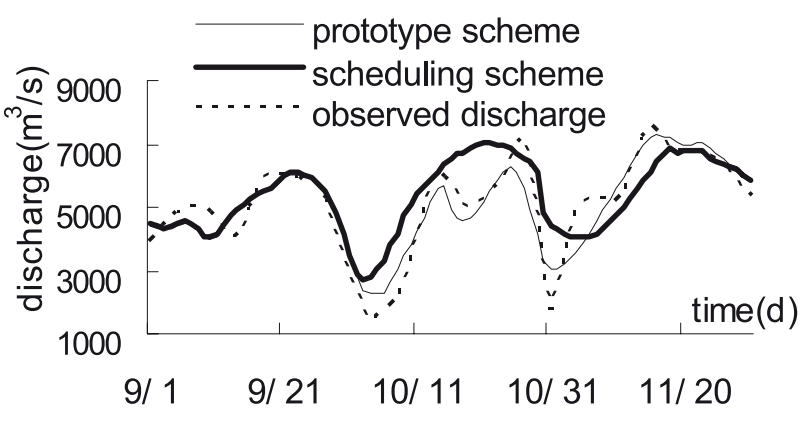

Fig. 11. Discharge hydrograph at Hukou station under scenario schemes.

and the total increase of water flowing into the Yangtze is about 18 billion $\mathrm{m}^{3}$. From October 21 to November 5 the discharge at Hukou shows a decreasing process of positive increments, and the average discharge increases $1,104 \mathrm{~m}^{3} / \mathrm{s}$, and the total increment of water flowing into the Yangtze is about 15 billion $\mathrm{m}^{3}$. From November 6 to November 14 the discharge at Hukou shows an increasing process of negative increments, and the average discharge decreased $749 \mathrm{~m}^{3} / \mathrm{s}$, and the total reduction of water flowing into the Yangtze is about 6 billion $\mathrm{m}^{3}$. From November 15 to November 30 the discharge at Hukou station shows a decreasing process of negative increments, and the average discharge decreased $315 \mathrm{~m}^{3} / \mathrm{s}$, and total reduction of water quantity flowing into the Yangtze is about 4 billion $\mathrm{m}^{3}$.

Finally, the discharge at Hukou presents a slow recovery process after the fluctuation and impact of the TGP impoundment on water regime at Hukou station gradually disappears. Thus, the TGP impoundment changes the original hydraulic relationship between the Yangtze and Poyang, and the hydraulic gradient at Hukou increases, leading to an increase in lake outflow, which expedites the decline of water level, and in turn the decline of water level and the decrease of water storage leads to the decrease of the lake outflow, which is even lower than the lake outflow without impoundment. Under the interaction between the Yangtze and Poyang, the lake outflow fluctuates dynamically and regularly with the increase and reduction of the impounding flow. Due to the impact of the TGP impoundment on the change of water regime at Hukou station, the water regime of Poyang Lake region also changes greatly. From the water level hydrograph of Poyang Lake region (Figs 12-13), it can be seen that the reduction process of water level in lake region presents the shape of a single peak type, reflecting the water storage function for the inflowing water. The average reduction amplitudes for the water level at Xingzi, Tangyin, Duchang, Kangshan, and Wucheng stations are $0.95 \mathrm{~m}, 0.70 \mathrm{~m}$, $0.74 \mathrm{~m}, 0.35 \mathrm{~m}$, and $0.80 \mathrm{~m}$, respectively, and the maximum reduction amplitudes of the water level are 1.339 $\mathrm{m}, 0.959 \mathrm{~m}, 1.102 \mathrm{~m}, 0.662 \mathrm{~m}$, and $1.108 \mathrm{~m}$, respectively, and the dates at which the maximum reduction amplitude of the water level occurred are October 24, October 23, October 24, October 25, and October 25, respectively. 


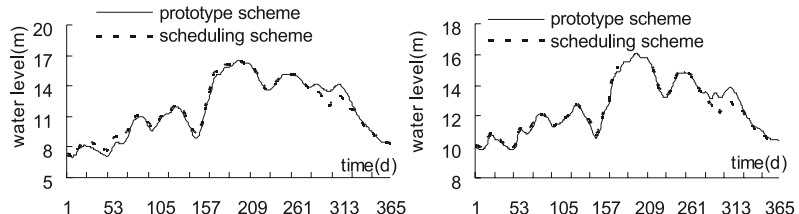

Fig. 12. Water-level hydrograph at Xinzi and Tangyin stations under scenario schemes.
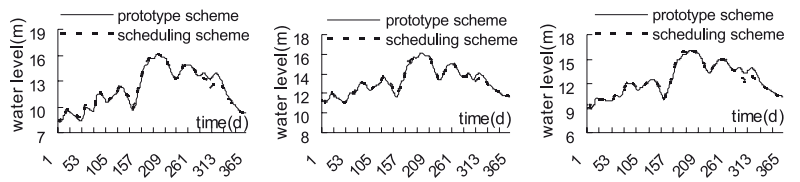

Fig. 13. Water-level hydrograph at Duchang, Kangshan, and Wucheng stations under scenario schemes.

Some researchers have investigated the water exchange between the Yangtze and the Poyang and the change of the lake water level during the TGP operation. Zhao et al. analyzed the annual runoff distribution of Hukou station at the lake's outlet of from 1990 to 2010 and drew the conclusion that the percentage of runoff in September and October increased by 2000 compared to that of the 1990s [39]. Zhang et al. demonstrated that modifications to the Yangtze flows from the Three Gorges Dam have had a much greater impact on seasonal (September-October) dryness of the lake compared to climate variability impacts on lake catchments, and the Yangtze's effects are attenuated in the lake regarding distance from the river, but nonetheless propagate some $100 \mathrm{~km}$ to the lake's upstream limit [40].

Liang et al. have concluded that the average water level at Xingzi station decreased by $0.90 \mathrm{~m}, 0.87 \mathrm{~m}$, and $0.85 \mathrm{~m}$ when the discharge capacity of TGP was reduced by $8,300 \mathrm{~m}^{3} / \mathrm{s}, 6,200 \mathrm{~m}^{3} / \mathrm{s}$, and $5,000 \mathrm{~m}^{3} / \mathrm{s}$, respectively [16]. Shi et al. have revealed that the average water level at Xingzi station decreased by about $0.83-1.36 \mathrm{~m}$ and the maximum water level decreased by about $1.37-3.65 \mathrm{~m}$ under the coming water conditions during 1991 to 2000 [19]. Lai et al. have concluded that the maximum reduction amplitude of water level at Xingzi Station was $1.55 \mathrm{~m}$ and that the average dropping amplitude of water level was about $0.74 \mathrm{~m}$ under the coming water conditions of 2006 [14]. Chen et al. have concluded that the water level at Hukou station decreased by $0.4-1.6 \mathrm{~m}$ and that the water level in the Poyang Lake region decreased accordingly by $0.3-1.2 \mathrm{~m}$ in the four typical years [15].

Although the existing research results are not the same, the changing trend of water level is consistent. Due to the change of the Yangtze water regime, the nearer the water area in the Poyang region to the Yangtze, the more obvious the influence caused by the TGP impounding. Therefore, the "pulling function" formed by the decrease in the Yangtze water levels results in the increase of the outflow at Hukou and the decline of the lake water level, and the reduction amplitude of water level decreases from north to south gradually.

\section{The Influence of TGP Impounding on Poyang Water Quality}

In order to study the impact of the TGP impoundment on the tempo-spatial distribution of ammonia nitrogen in the Poyang region, the reference points for water quality analysis are selected as follows: No. 1, near Hukou, represents the region where water of the lake area is frequently exchanged with that of the Yangtze; No. 2, near Xinzi, represents the critical region where lake area water is exchanged with that of the Yangtze; No. 3, which is set on the right side of the lake's middle region, represents the main channel where water flow moves; and No. 4, set near the entrance of the Ganjiang River, represents the "five rivers" downstream. The calculation period for water quality is set on September 17 to November 30 . The calculated ammonia nitrogen hydrograph under two scenarios are shown as Figs 14 and 15.

According to the discharge hydrograph of the outlet for Poyang Lake (Fig. 11), the water flow has been entered into the mainstream of the Yangtze without backward flow. The outflow of the scheduling scheme is larger than that of the prototype scheme from October 2 to November 5 , while the outflow of the prototype scheme is larger than that of the scheduling scheme from November 6 to November 30 . According to the changing process of the ammonia nitrogen at point No. 1, the ammonia nitrogen output at Hukou is 2,607 tons under the scheduling scheme and 1,747 tons under the prototype scheme between October 2 and November 6, and the former is 860 tons more than the latter. Between November 6 and November 30 , the ammonia nitrogen output at Hukou is 1,787 tons under the scheduling scheme and 1,980 tons under the prototype scheme, and the former is about 200 tons less than the latter. The above analysis shows that with the increase of water flowing into the Yangtze, the ammonia
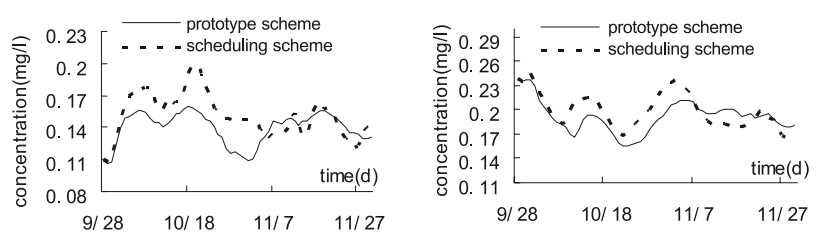

Fig. 14. Ammonia nitrogen hydrograph at Nos. 1 and 2 reference points under two scenario schemes.
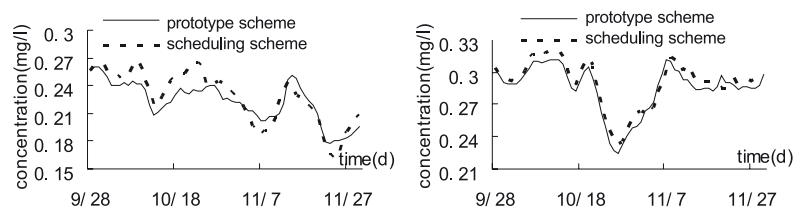

Fig. 15. Ammonia nitrogen hydrograph at Nos. 3 and 4 reference points under two scenario schemes. 
nitrogen output at Hukou increases 660 tons, which leads to a reduction of the total amount of ammonia nitrogen in the Poyang region under the scheduling scheme.

According to the tempo-spatial changing process of ammonia nitrogen (Figs 14-15), the concentration of ammonia nitrogen under the scheduling scheme is always higher than that of ammonia nitrogen under the prototype scheme before November 5, and after this the calculated concentrations under the two schemes are different. The spatial distribution of ammonia nitrogen concentration shows the north-south high-low trend, and the calculated ammonia nitrogen concentration at point No. 1 is relatively low while that at No. 4 is relatively high. The statistical results for ammonia nitrogen at the four points show that under different scenarios the fluctuation amplitudes of the ammonia nitrogen are 0.016$0.0434 \mathrm{mg} / \mathrm{l},-0.020-0.0417 \mathrm{mg} / \mathrm{l},-0.019-0.0307 \mathrm{mg} / \mathrm{l}$, and $-0.012-0.0129 \mathrm{mg} / \mathrm{l}$, respectively. The No. 1 point near Hukou is mostly affected while the No. 4 point near the Ganjiang downstream is least affected. The above analysis suggests that due to the TGP impoundment, the outflow at Hukou significantly increases and the water level of the lake region decreases, resulting in the water storage capacity of the lake becoming smaller and the pollutant self-purification capacity of the lake area declining. Therefore, the overall ammonia nitrogen concentration of the lake area has a slightly upward trend under the precondition that the water volume and ammonia nitrogen contents flowing into the lake are maintained at constant levels. Because of the narrow and deep river channel in the north, water flow speed increases and ammonia nitrogen degradation speeds up, which leads to the ammonia nitrogen concentration being relatively lower compared with that of the lake area. The TGP impoundment has some influence on ammonia nitrogen concentration of Poyang Lake, and the influence amplitude diminishes from north to south, while the ammonia nitrogen concentration grades (class II water standard) do not change because of the TGP impoundment.

$\mathrm{Wu}$ et al. have analyzed the TGP influence on water Poyang quality based on the field observed water quality data from 1999 to 2009, and drawn the conclusion that lake water quality shows a tendency to deteriorate, and the selfpurification capability of the lake is much weakened after

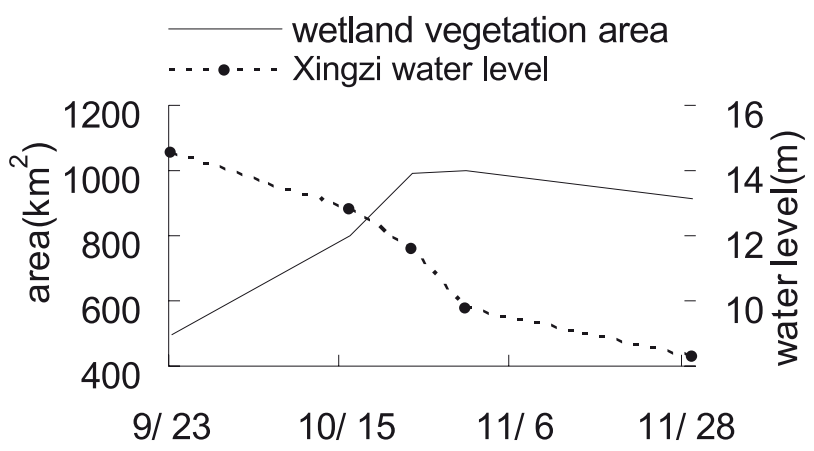

Fig. 16. Relationship between the wetland area of Xingzi.
2003 [41], which is similar to the conclusion of this paper. However, the ammonia nitrogen concentration variation of Poyang is related to many factors. From the view of the calculated concentration value, the water regime change of Poyang Lake caused by TGP impounding has some effect on ammonia nitrogen concentration; however, the places near the "five rivers" downstream are slightly affected. Because the Yangtze water does not flow back into Poyang during the TGP impoundment, independent of the Yangtze mainstream, Poyang ammonia nitrogen concentration is closely related to the inflows and its ammonia nitrogen contents flowing into the lake.

\section{Influence of TGP Impounding on Wetland Vegetation of Poyang Lake}

Table 2 shows the relationship between the wetland vegetation area of Poyang Lake and the water level of Xingzi Station between September 23 and November 29 (Fig. 16).

Assuming that the change rate of the wetland vegetation area with water level remains unchanged, the influence of water level change at Xingzi under the scenario schemes on the wetland vegetation area can be estimated. Based on the data in Fig. 16, the change rate of the wetland area with water level can be calculated. The wetland vegetation area will increase $169.03 \mathrm{~km}^{2}$ when the water level at Xingzi station falls one meter from September 23 to October 16 , and the wetland vegetation area will increase 158.06 $\mathrm{km}^{2}$ when the water level falls one meter from October 17 to October 24, and the wetland vegetation area will increase $5.44 \mathrm{~km}^{2}$ when the water level falls one meter from October 25 to October 31, and finally the wetland vegetation area will decrease $57.86 \mathrm{~km}^{2}$ when the water level falls one meter from November 1 to November 29.

According to the calculated water level under the scenarios schemes from September 30 to November 30 and the piecewise linear relationship between the wetland vegetation area and the water level of Xingzi station, the time-varying process of wetland vegetation area in Poyang is obtained by the interpolating method as shown in Fig. 17, from which it can be seen that the maximum and minimum wetland vegetation area in Poyang under the prototype scheme are $999.79 \mathrm{~km}^{2}$ and $614.02 \mathrm{~km}^{2}$, which

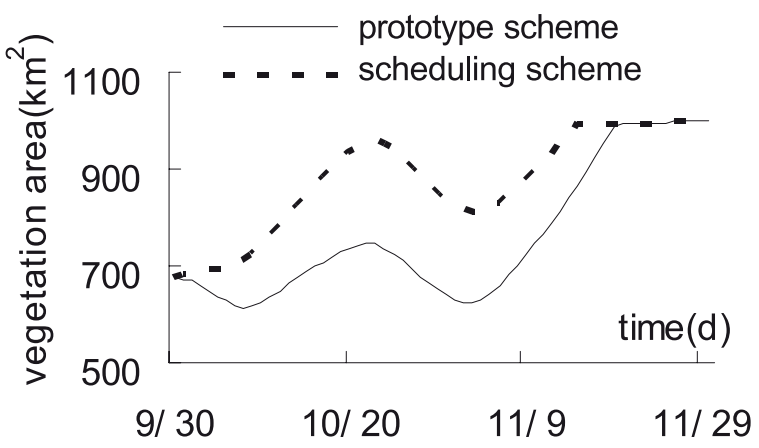

Fig. 17. Variation of wetland area under water levels scenario schemes. 
appeared on November 30 and October 8, respectively. The maximum and minimum wetland vegetation area under the scheduling scheme are $1,000.56 \mathrm{~km}^{2}$ and 678.25 $\mathrm{km}^{2}$, which appeared on November 30 and September 30 , respectively. The wetland vegetation area under two scenario schemes range from 0.64 to $215.48 \mathrm{~km}^{2}$, in which the maximum amplitude occurs on October 24 and the minimum amplitude occurs on November 27 , and the time that the maximum amplitude occurs corresponds to that of the maximum reduction of water level at Xinzi. The above analysis indicates that as a result of the water level decline in advance, the wetland vegetation area dynamically presents the increasing fluctuation with the declining range of the water level after the TGP impounding.

$\mathrm{Hu}$ et al. have found that there was a dramatic decrease in areas of mudflat and water in September and October because the TGP had a more prominent influence on the decline of Poyang water level [21]. Feng et al. have carried out the analysis of long-time hydrological and meteorological data and concluded that while local precipitation remained stable, Poyang water level decreased significantly after TGP impoundment, which is likely the main reason for the wetland expansion in recent years [42]. These two research results indirectly prove the rationality of the conclusion of this paper.

The Influence of TGP Impoundment on the Bottomland Exposure of Poyang Lake

The marshland is exposed and submerged regularly with the water level change within the protection zone of Poyang Lake, and the date that the wetland is exposed or submerged, the scope, and the duration mainly depend on water level amplitude and ground elevation [38]. The elevation of bottomland wetland in the south is high while in the north it is low, the bottomland elevation of Xingzi Lake is $10-13 \mathrm{~m}$, that of Duchang Lake is $11-14 \mathrm{~m}$, that of Wucheng Lake is $12-16 \mathrm{~m}$, and the bottomland wetland of the elevation 11-14 $\mathrm{m}$ is the most suitable habitat for wintering migratory birds [43]. The cares community is the most important vegetation type in Poyang Lake bottomland and is also the main food source for migratory birds. When the water level is below the lower limit of the cares community elevation, it will adversely affect the foraging and the normal wintering life for migratory birds. The elevation of the spatial distribution for the cares community in the south is high, while in the north it is low, and the elevation of Xingzi Lake is $13.0-14.5 \mathrm{~m}$, that of Duchang Lake is $13.5-15.0 \mathrm{~m}$, and that of Wucheng Lake is $14.5-16.0 \mathrm{~m}$ [43]. According to the calculated water level under the scheduling scheme at Xingzi, Wucheng, and Duchang stations, the impact of the water level variation on bottomland exposure is analyzed as shown in Table 3.

From the data in Table 3 it can be seen that the bottomland of Xingzi station with $13 \mathrm{~m}$ elevation is exposed from November 13 to November 30 by analyzing the measured water level data, while due to the TGP impoundment the exposure date is from October 12 to November 30 by analyzing the calculated water level data, which is obviously 32 days in advance. The bottomland of Xingzi station with $12 \mathrm{~m}$ elevation is actually exposed from November 19 to November 30, while due to the TGP impoundment the exposure date is from October 20 to October 25 and from November 12 to November 30, which is obviously 13 days in advance. The bottomland of Xingzi station with $11 \mathrm{~m}$ elevation is actually exposed from November 26 to November 30, while due to the TGP impoundment the exposure date is from November 21 to November 30, which is five days in advance. The

Table 3. Impact of TGP impoundment water on bottomland exposure.

\begin{tabular}{|c|c|c|c|c|c|c|}
\hline $\begin{array}{c}\text { Station } \\
\text { name }\end{array}$ & $\begin{array}{c}\text { Bottomland } \\
\text { elevation }\end{array}$ & $\begin{array}{c}\text { Actual } \\
\text { exposure time }\end{array}$ & $\begin{array}{c}\text { Actual days } \\
\text { of continuous } \\
\text { Exposure }\end{array}$ & $\begin{array}{c}\text { Exposure time } \\
\text { after impoundment }\end{array}$ & $\begin{array}{c}\text { Exposure days } \\
\text { in advance after } \\
\text { impoundment }\end{array}$ & $\begin{array}{c}\text { Continuous } \\
\text { exposure days after } \\
\text { impoundment }\end{array}$ \\
\hline \multirow{5}{*}{ Xinzi } & 13 & Nov. 13 to Nov. 30 & 18 & Oct. 12 to Nov. 30 & 32 & 50 \\
\cline { 2 - 8 } & 12 & Nov. 19 to Nov. 30 & 12 & $\begin{array}{c}\text { Oct. } 20 \text { to Oct. } 25 \\
\text { Nov. } 12 \text { to Nov. } 30\end{array}$ & 13 & 25 \\
\cline { 2 - 8 } & 11 & Nov. 26 to Nov. 30 & 5 & Nov. 21 to Nov. 30 & 5 & 3 \\
\hline \multirow{5}{*}{ Duchang } & 14 & $\begin{array}{c}\text { Oct. } 1 \text { to Oct. } 5 \\
\text { Nov. } 5 \text { to Nov. } 30\end{array}$ & 57 & Oct. 1 to Nov. 30 & 4 & 61 \\
\cline { 2 - 8 } & 12 & Nov. 13 to Nov. 30 & 18 & Oct. 14 to Nov. 30 & 30 & 48 \\
\hline \multirow{5}{*}{ Wucheng 19 to Nov. 30} & 12 & Nov. 14 to Nov. 30 & 5 & 17 \\
\cline { 2 - 8 } & 11 & Nov. 29 to Nov. 30 & 2 & Nov. 21 to Nov. 30 & 8 & 10 \\
\hline & 13 & $\begin{array}{c}\text { Oct. } 1 \text { to Oct. } 5 \\
\text { Oct. } 15 \text { to Oct. } 27\end{array}$ & 42 & Oct. 1 to Nov. 30 & 19 & 61 \\
\hline
\end{tabular}


bottomland of Xingzi station with $10 \mathrm{~m}$ elevation is actually not exposed, while due to TGP impoundment the exposure date is from November 28 to November 30 for only three days of continuous exposure after impoundment.

Based on the above analysis, it can be concluded that the Poyang water level falls in advance and the continuous exposure days increase due to the TGP impoundment. Therefore, the wetland wound dries in advance, which is not conducive for migratory birds. Especially when encountering the lower water level of Poyang Lake, the TGP impoundment will further aggravate the decline of lake levels, further impacting migratory birds. The vegetation changes caused by the changes of hydrological conditions have appeared in part of Poyang [20-21]. Due to the TGP impoundment, the days when the bottomland are submerged decrease and that of exposure increase, which will further accelerate the degradation of wetland vegetation.

\section{Conclusions}

For this paper we developed a numerical model for simulating water quantity and quality in Poyang Lake based entirely on the hydraulic method, and then applied it to assess the impact of TGP impoundment on the environment of Poyang Lake in 2000. Significant conclusions are:

1. Due to the TGP impoundment, the hydraulic gradient and the lake outflow at Hukou increase, leading to the water level decline in advance. The average water level at the Xingzi, Tangyin, Duchang, and Kangshan stations decreased $0.95 \mathrm{~m}, 0.70 \mathrm{~m}, 0.74 \mathrm{~m}, 0.35 \mathrm{~m}$, and $0.80 \mathrm{~m}$, respectively. In turn, the decline of water level and the decrease of water storage of the lake lead to a decrease in lake outflow, which is even lower than lake outflow without the impoundment. The lake outflow fluctuates dynamically and regularly with the increase and decrease of the TGP released flow.

2. The influence of the TGP impoundment on water quality of Poyang Lake is high in the north and low in the south, and the reduction amplitude decreases gradually from north to south. The nearer the water area in Poyang Lake region to the Yangtze River, the more obvious the influence caused by TGP impounding.

3. Due to TGP impounding, the ammonia nitrogen output at Hukou increases and the total amount of ammonia nitrogen in Poyang decreases, while the overall ammonia nitrogen concentration within lake area presents an upward trend. Under the hydrological conditions of 2000, the output amount of ammonia nitrogen increases 660 tons with the increase of the water outflow into the Yangtze.

4. The water regime change of Poyang Lake caused by TGP impounding has little effect on ammonia nitrogen concentrations, especially the places near the "five rivers" downstream that are slightly affected. The influence amplitude diminishes from north to south gradually. The ammonia nitrogen concentration of Poyang is closely related to the water volumes and its ammonia nitrogen contents entering into the lake.

5. As a result of water levels falling in advance, the wetland vegetation area presents the dynamic fluctuation with the decline range of the water level. The wetland vegetation area under the scenario schemes ranges from 0.64 to $215.48 \mathrm{~km}^{2}$, in which the time the maximum amplitude occurs corresponding to the maximum reduction of water levels at Xinzi.

6. Due to TGP impounding, the Poyang water level falls in advance, and the continuous exposure days increase and the wetland becomes dry in advance, with a result that the feed of birds relying on the shallow water wetland to forage and rest is reduced greatly, which is not conducive to protecting migratory birds. The days when the bottomland are submerged decrease and that of exposure increase, which will further accelerate the degradation succession of wetland vegetation.

In further discussion, the influence of TGP impounding the Poyang Lake water ecosystem is the result of a longterm accumulation process. Only through long-term observation and tracking research can deeply elucidate the relationship between the Poyang Lake ecosystem and the TGP operation.

\section{Acknowledgements}

Our research was financially supported by project No. 41471014 sponsored by the National Natural Science Foundation of China.

\section{References}

1. SUN Z., HUANG Q., OPP C., HENNIG T., MORALD U. Impacts and implications of major changes caused by the Three Gorges Dam in the middle reaches of the Yangtze River, China. Water Resource Management. 26 (12), 3367, 2012.

2. WANG J.D., SHENG Y.W., D.TONG T.S. Monitoring decadal lake dynamics across the Yangtze Basin downstream of Three Gorges Dam. Remote Sensing of Environment. 152, 251, 2014.

3. CAO L., FOX A.D. Birds and people both depend on China's wetlands. Nature .460, 173, 2009.

4. YI Y.J., WANG Z.Y., YANG Z.F. Impact of the Gezhouba and Three Gorges Dams on habitat suitability of carps in the Yangtze River. Journal of Hydrology. 387, 283, 2010.

5. YUAN W.H., YIN D.W., FINLAYSON B., CHEN Z.Y. Assessing the potential for change in the middle Yangtze River channel following impoundment of the Three Gorges Dam. Geomorphology. 147, 27, 2012.

6. GAO B., YANG D.W., YANG H.B. Impact of the Three Gorges Dam on flow regime in the middle and lower Yangtze River. Quaternary International. 304, 43, 2013.

7. GAO J.H., JIA J.J, J.KETTNER A, XING F., WANG Y.P., XU X.N. Changes in water and sediment exchange between the Changjiang River and Poyang Lake under natural and anthropogenic conditions, China. Science of Total Environment. 481, 542, 2014. 
8. HU Q., FENG S., GUO H., CHEN G., JIANG T. Interactions of the Yangtze river flow and hydrologic processes of the Poyang Lake, China. Journal of Hydrology. 347 (1-2), 90, 2007.

9. ZHANG Z.X., CHEN X., XU C.Y., HONG Y., HARDY J., SUN Z.H. Examining the influence of river-lake interaction on the drought and water resources in the Poyang Lake basin. Journal of Hydrology. 522, 510, 2015.

10. PU P.M., CAI S.M., ZHU H.H., LI,W.B. The Three Gorges Project and lake depression environment in the middle reaches of the Yangtze River. Beijing Science Press, China 1994.

11. LIU Y.B., WU G.P., ZHAO X.S. Recent declines in China's largest freshwater lake: trend or regime shift? Environmental Research Letters. 8 (1), 1, 2013.

12. ZHANG Q., LI L., WANG Y.G., WERNER A.D., XIN P.T., JIANG D.A. Has the Three Gorges Dam made the Poyang Lake wetlands wetter and drier? Geophysical Research Letters. 39 (20), 1, 2012.

13. GUO H., HU Q., ZHANG Q., FENG S. Effects of the Three Gorges Dam on Yangtze River flow and river interaction with Poyang Lake, China: 2003-2008. Journal of Hydrology. s416-417 (2), 19, 2012.

14. LAI X.J., LIANG Q.H., JIANG J.H., HUANG Q. Impoundment effects of the Three Gorges Dam on flow regimes in two China's largest freshwater lakes. Water Resources Management. 28 (14), 5111, 2014.

15. CHEN J., XU J.J. Study on the impact of the Three Gorges Reservoir on Poyang Lake and some proposals. Journal of Hydraulic Engineering. 44 (7), 757, 2013.

16. LIANG Z.M., WANG J. Study on the impact of the Three Gorges Project operation on flood control of Poyang Lake. Hohai University Press, Nanjing 2010.

17. LI S.Q., WEN J., TAN G.L., PAN H.M., CHEN J.L. The cause analysis of low water characteristics of Poyang Lake in 2006.Journal of China Hydrology. 8 (6), 73, 2008.

18. JIANG J.H., HUANG Q. A study of the impact of the Three Gorges Project on the water level of Poyang Lake. Journal of Natural Resources. 12 (3), 219, 1997.

19. SHI Y., LUAN Z.Y. A study of the impact of the Three Gorges Project on the water level of Poyang Lake and the "five rivers". Nanjing Water Conservancy Science Research Institute, Nanjing 2010.

20. YU L., HE L.H., ZHANG Q., CHEN Y.W., WANG X.L. Effects of the Three Gorges Project on the typical wetland vegetations of Poyang Lake. Geographical Research. 30 (1), 134, 2011.

21. HU Y.X., HUANG J.L., DU Y., HAN P.P., WANG J.L., HUANG W. Monitoring wetland vegetation pattern response to water-level change resulting from the Three Gorges Project in the two largest freshwater lakes of China. Ecological Engineering. 74, 274, 2015.

22. SHANKMAN D., LIANG Q. Landscape changes and increasing flood frequency in China's Poyang Lake region. Prof Geogr. 55, 434, 2003.

23. ZHU H.H., ZHANG B. The Poyang Lake. Press of University of Science and Technology of China, Hefei 1997.

24. ROGERS B., FUJIHARA M., BORTHWICK A.G.L. Adaptive Q-tree Godunov-type scheme for shallow water equation. Int.J.Numer.Methods Fluids. 35, 247, 2001.
25. WANG D.G. Computational hydraulics theory and application. Hohai University Press, Nanjing, China 1989.

26. CUNGE J.A., HOLLY F.M., VERWEY A. Practical Aspects of Computational River Hydraulics. Pitman Advanced Publishing Program, London 1980.

27. ZHAO D.H., SHEN H.W., LAI J.S., TABIOS III G.Q. Approximate Riemann Solvers In FVM For 2D Hydraulic Shock Wave Modeling.Journal of Hydraulic Engineering. 122 (12), 692, 1996.

28. MORGAN R.B. A restarted GMRES method augmented with eigenvectors. SIAM J. Matrix Anal.Appl. 16, 1112, 1995.

29. SAAD Y. A flexible inner-outer preconditioned GMRES algorithm. SIAM J Sci Comput. 14 (2), 461, 1993.

30. LAI X.J., WANG D.G.1-D and 2-D Coupling numerical model of unsteady flows. Hydro-Science and Engeering. 2, 48, 2002.

31. HU S.Y., SHI Y., QI C. Systematic analysis on abnormally high flood stages of middle Yangtze River in 1998.Advances in Water Science. 10 (3), 242, 1998.

32. HU S.Y., SHI Y., WANG Y.T. Numerical simulation of flood routing for the middle-lower Yangtze River system. Advances in Water Science. 13 (3), 278, 2002.

33. LAI X.J., JIANG J.H., LIANG Q.H. Large-scale hydrodynamic modeling of the middle Yangtze River Basin with complex river-lake interactions. Journal of Hydrology. 492, 228, 2013.

34. WANG S.R., SHU J.M., NI Z.K., FENG M.L. Investigation on pollution situation and countermeasures. Journal of Environmental Engineering Tecnology. 3 (4), 342, 2013.

35. ZHU J.D., XU H.C. Water quality model for river network and numerical simulation. Journal of Hohai University. 20 (1), 16, 1992.

36. ZHANG S.N. Environmental hydraulics. Hohai University Press, Nangjing, China 1988.

37. DU Y.L., ZHOU H.D., PENG W.Q. Modeling the impacts of the change of river-lake relationship on the hydrodynamic and water quality revolution in Poyang Lake. Acta Scientiae Circumstantiae. 35 (5), 1274, 2015.

38. DONG Z.C., LI D.Y. The effect of the Three Gorges Project on the water environment of Poyang Lake. Hohai University Press, Nangjing, China 2010.

39. ZHAO J.K., LI J.F., YAN H., ZHENG L., DAI Z.J. Analysis on the water exchange between the main stream of the Yangtze River and the Poyang Lake. Procedia Environmental Sciences. 10, 2256, 2011.

40. ZHANG Q., YE X.C., WERNER A.D., LI Y.L., YAO J., LI X.H. An investigation of enhanced recessions in Poyang Lake: Comparison of Yangtze River and local catchments impacts. Journal of hydrolody. 517, 425, 2014.

41. WU L.H., LI W., GUO Y.Y., YANG X.L. Influence of Three Gorges Project on Water quality of Poyang Lake. Procedia Environmental Sciences. 10, 1496, 2011.

42. FENG L., HAN X.X., HU C.M., CHEN X.L. Four decades of wetland changes of the largest freshwater lake in China: Possible linkage to the Three Gorges Dam? Remote Sensing of Environment. 176, 43, 2016.

43. LIU Q., YAN B.Y., GE G., TAN H.R. The theory and practice of ecological restoration of Poyang Lake wetland. China Science Press, China 2012. 